\title{
OSTEOSARCOMA OF THE SCAPHOID
}

\author{
A CASE REPORT AND REVIEW OF THE LITERATURE
}

\begin{abstract}
AUGUSTO MARCUZZI, ANTONIO MAIORANA, ROBERTO ADANI, VINCENZO SPINA, RICCARDO BUSA, ALESSANDRO CAROLI
\end{abstract}

From the University of Modena, Italy

W e describe a case of osteosarcoma of the scaphoid bone, which to our knowledge is only the second reported case of osteosarcoma in the carpus. A 38-year-old man complained of intense pain in the right wrist and had curettage and a bone graft for a lesion in the scaphoid. Histological examination showed this to be an osteosarcoma. Below-elbow amputation was performed and adjuvant chemotherapy given. There has been no evidence of recurrence or metastases at 33 months after amputation.

J Bone Joint Surg [Br] 1996;78-B:699-701.

Received 22 March 1996; Accepted 22 April 1996

Osteosarcomas are malignant tumours characterised by the direct formation of osteoid or immature bone by malignant cells. They occur most often in adolescents during the period of maximum growth and appear to be related to increased osteoblastic activity. Osteosarcomas usually develop in long bones, such as the femur, tibia and humerus, showing a predilection for metaphyseal areas. Their occurrence in short and flat bones is less common with the iliac and facial bones being most often affected.

The development of an osteosarcoma in the carpal bones is extremely rare. We could find only one documented case in an extensive search of the literature (Bickerstaff, Harris and Kay 1988). The rarity of the lesion, together with its

\footnotetext{
A. Marcuzzi, MD, Hand Surgeon

R. Adani, MD, Hand Surgeon

R. Busa, MD, Hand Surgeon

A. Caroli, MD, Professor of Hand Surgery

A. Maiorana, MD, Pathologist

V. Spina, MD, Radiologist

University of Modena, Policlinico, Largo del Pozzo, 71-41100 Modena, Italy.
}

Correspondence should be sent to Dr A. Marcuzzi.

(C)1996 British Editorial Society of Bone and Joint Surgery 0301-620X/96/51262\$2.00 misleading clinical and radiological features, prompted us to report our case.

\section{CASE REPORT}

A 38-year-old man was seen in September 1993 complaining of intense pain on the radial aspect of the right wrist for more than a year which was relieved by aspirin. He had had an operation at another hospital seven months previously for a 'mass' in the right wrist. This had been histologically diagnosed as "synovial hyperplasia and chondrocalcinosis". Two months after operation his symptoms returned and became more severe with marked enlargement of the wrist.

Examination revealed a painful swelling over the radial aspect of the right wrist. Active movement was reduced with a lack of $40^{\circ}$ of extension and $45^{\circ}$ of flexion.

Plain radiography showed osteolytic lesions in the scaphoid intermixed with areas of sclerosis and isolated calcification in the tubercle. The surrounding soft tissues showed increased density (Fig. 1). Blood tests were within the normal range.

Axial CT showed a round radiolucent lesion in the central part of the scaphoid vaguely suggestive of a 'nidus'. There was a small cortical interruption with increased density of surrounding soft tissues (Fig. 2). The T1-weighted (TR/TE 500/20) coronal MR images before and after administration of gadolinium diethylene triaminepenta-acetic acid (Gd-DTPA) showed an intraosseous mass, which appeared to extend outside the bone. The signal characteristics were non-specific, with homogeneous low signal intensity on the T1-weighted image and high signal intensity on the T2-weighted and T1-weighted Gd-DTPA images (Fig. 3).

An osteoid osteoma was suspected; the lesion was curetted and packed with cancellous bone chips obtained from the ipsilateral olecranon. A diagnosis of osteosarcoma was made after histological examination and below-elbow amputation was performed with adjuvant chemotherapy using methotrexate, cysplatin and adriamycin. Thirty-three months after amputation there is no evidence of recurrence or of metastatic disease.

Histological examination. The specimen consisted of multiple small, gritty, osteocartilaginous fragments, the largest of which measured $5 \times 2 \mathrm{~mm}$. The material was fixed in 


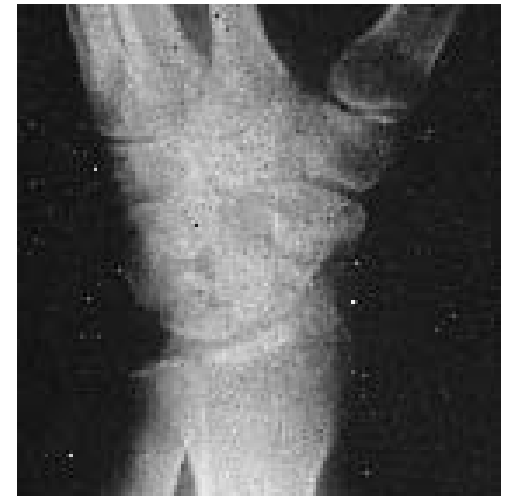

Fig. 1

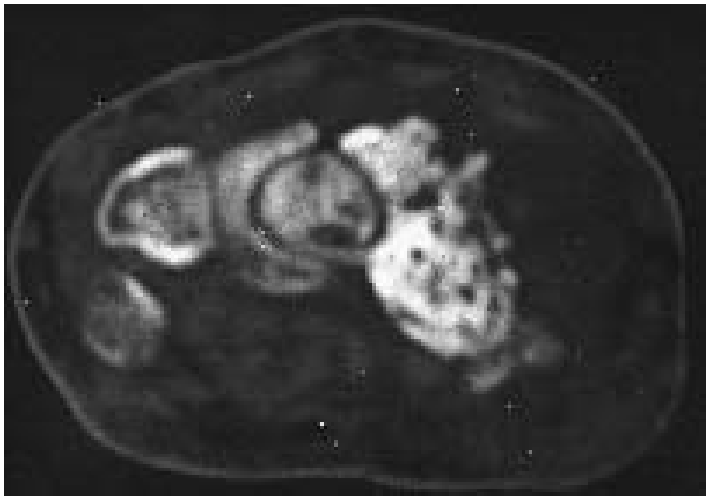

Fig. 2

Figure 1 - Plain anteroposterior radiograph taken seven months after the first operation on the hand showing irregular lytic destruction of the scaphoid with multiple calcified areas. Figure 2 - Axial CT of the wrist showing the small lytic lesion of the scaphoid with increased density of the surrounding soft tissues. Bone sclerosis was initially interpreted as being suggestive of osteoid osteoma.

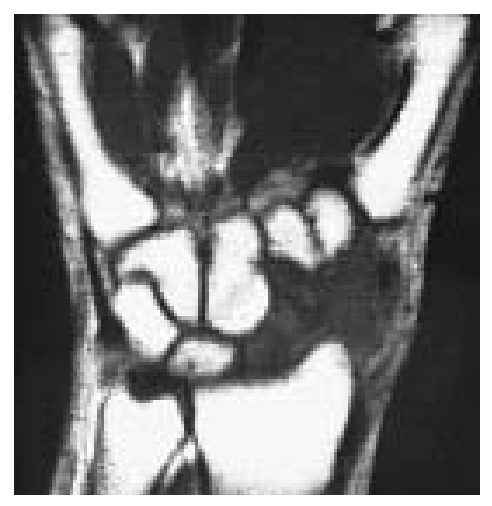

Fig. 3a

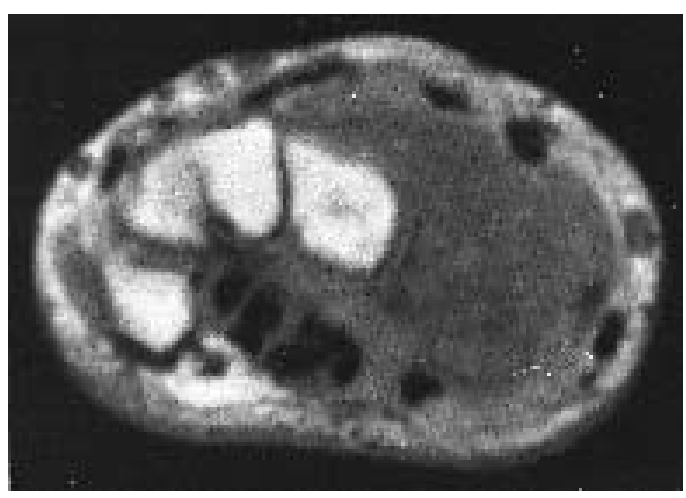

Fig. $3 b$

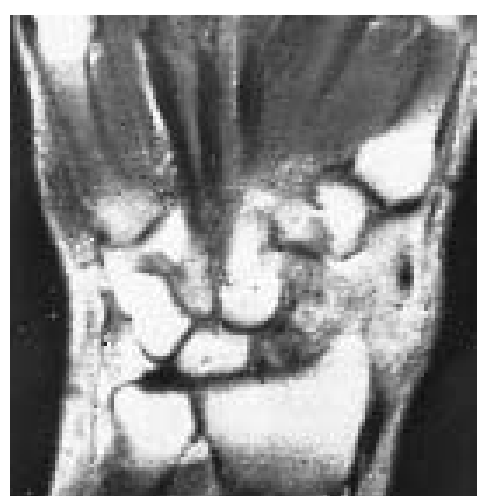

Fig. 3c

Figures $3 a$ and $3 b$ - Coronal T1-weighted (TR/TE 560/20) and axial T2-weighted images (TR/TE 2000/80) showing abnormal signal intensity of the scaphoid and a large soft-tissue mass with inhomogeneous high signal intensity. Figure 3c - Coronal T1-weighted image (TR/TE 600/20) after intravenous administration of Gd-DTPA showing intense enhancement.

$4 \%$ formaldehyde and embedded in paraffin. Sections were stained with haematoxylin and eosin. Histological examination showed bone trabeculae with hypercellular medullary spaces containing osteoid-forming round cells with hyperchromatic nuclei. Isolated, mostly typical mitotic figures were present. Areas of cartilaginous tissue were intermixed with bone fragments and contained chondrocytes with plump, often bizarre, hyperchromatic nuclei showing frequent multinucleations (Fig. 4).

\section{DISCUSSION}

Although isolated cases of osteosarcoma have been reported in the small tubular bones of the hands (Carroll, Godwin and Watson 1956; Fleegler et al 1980; Okada et al 1993) and feet (Mirra et al 1988), the presence of this tumour in the carpal bones is exceptional. The case reported by Bickerstaff et al (1988) was of a low-grade osteosarcoma of the trapezium which was initially treated by local amputation of the thumb and index finger along with the trapezium, trapezoid, scaphoid and part of the radial styloid. A recurrence was seen in the metacarpals a year later. The radiological appearance was more aggressive and aboveelbow amputation was then carried out. No evidence of recurrence or metastasis was detected at the time of publication of the report nine months later.

Our case was similar to that of Bickerstaff et al (1988) and is unusual in that it occurred in a middle-aged man without risk factors, such as Paget's disease or exposure to radiation. Of the 25 cases of osteosarcoma of the hand reported (Carroll et al 1956; Fleegler et al 1980; Okada et al 1993), two were associated with Paget's disease and a further three had had frequent irradiation or injection of radioactive material.

The differential diagnosis of osteosarcoma of the carpus includes benign conditions such as osteoid osteoma and rare localisations of fibrous dysplasia or desmoplastic fibroma (Okada et al 1993). The clinical finding of bone pain and swelling in the overlying soft tissues may result in a mistaken diagnosis of osteoid osteoma (Ellman, Gold and Mirra 1974; Woods et al 1993). The lack of a well-defined 'nidus' on radiological examination and the histological 


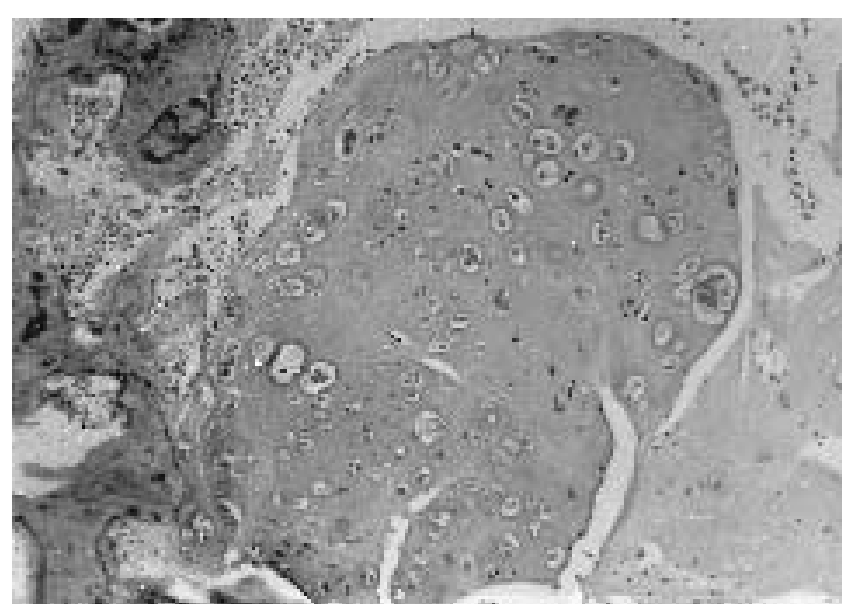

Fig. 4a

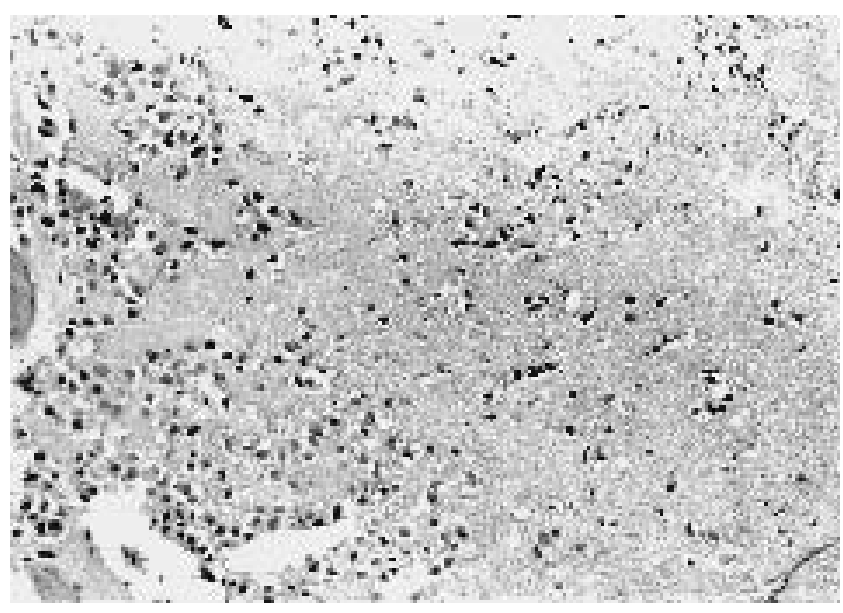

Fig. 4b

Figure $4 \mathrm{a}-$ Area of cartilaginous tissue containing atypical chondrocytes (haematoxylin and eosin $\times 120$ ). Figure $4 \mathrm{~b}-$ The medullary spaces are infiltrated by atypical cells (haematoxylin and eosin $\times 85$ ).

finding of cytologically atypical chondral tissue with permeation of tumour cells between the bone trabeculae led to the diagnosis of osteosarcoma. Fibrous dysplasia localises in a carpal bone mainly in diffuse forms and is distinguishable histologically.

The prognosis for patients with osteosarcoma of the carpus is as yet undefined, due to the paucity of reports. Osteosarcomas of the hand have been reported to behave less aggressively than those arising in other sites (Okada et al 1993), although Clark (1952) suggested that early detection may be in part responsible for the relatively good outcome.

The treatment of choice appears to be wide amputation, since excision of a ray can be followed by local recurrence, as seen in the case of Bickerstaff et al (1988). The effectiveness of chemotherapy is not clear, but we believe that it should be included in the treatment until further experience proves otherwise.
No benefits in any form have been received or will be received from a commercial party related directly or indirectly to the subject of this article.

\section{REFERENCES}

Bickerstaff DR, Harris SC, Kay NR. Osteosarcoma of the carpus. $J$ Hand Surg [Br] 1988;13:303-5.

Carroll RE, Godwin JT, Watson WL. Osteogenic sarcoma of phalanx after chronic roentgen-ray irradiation. Cancer 1956;9:753-5.

Clark CE. Osteogenic sarcoma of the finger. Am J Surg 1952;83:112-4.

Ellman H, Gold RH, Mirra JM. Roentgenographically 'benign' but rapidly lethal diaphyseal osteosarcoma: a case report. J Bone Joint Surg [Am] 1974;56-A:1267-9.

Fleegler EJ, Marks KE, Sebek BA, Groppe CW, Belhobek G. Osteosarcoma of the hand. Hand 1980;12:316-22.

Mirra JM, Kameda N, Rosen G, Eckardt J. Primary osteosarcoma of toe phalanx: first documented case: review of osteosarcoma of short tubular bones. Am J Surg Pathol 1988;12:300-7.

Okada K, Wold LE, Beabout JW, Shives TC. Osteosarcoma of the hand: a clinicopathologic study of 12 cases. Cancer 1993;72:719-25.

Woods ER, Martel W, Mandell SH, Crabbe JP. Reactive soft-tissue mass associated with osteoid osteoma: correlation of MR imaging features with pathologic findings. Radiology 1993;186:221-5. 